\title{
Effects of Chocolate Milk Supplementation on Recovery from Cycling Exercise and Subsequent Time Trial Performance
}

Author Block: Lisa Ferguson-Stegall, Erin McCleave, Phillip G. Doerner, Zhenping Ding, Benjamin Dessard, Lynne Kammer, Bei Wang, Yang Liu, and John L. Ivy, FACSM.

Exercise Physiology and Metabolism Laboratory, Department of Kinesiology, University of Texas at Austin, Austin, TX.

First author classification: Doctoral candidate

Email: lisastegall@gmail.com

PURPOSE: Supplementing with carbohydrate plus protein following strenuous endurance exercise has been found to improve both recovery and subsequent aerobic endurance performance beyond that of a carbohydrate supplement alone. The purpose of the present study was to compare the effects of chocolate milk $(\mathrm{CM})$, an isocaloric carbohydrate only supplement $(\mathrm{CHO})$, and placebo (PLA) on markers of endurance exercise recovery and subsequent time trial performance in trained cyclists. METHODS: Ten trained male and female cyclists (5 males, 5 females) performed 3 trials in which they first cycled for $1.5 \mathrm{~h}$ at $70 \%$ of $\mathrm{VO}_{2} \mathrm{max}$, followed by 10 min of intervals that alternated $45 \%$ and $90 \%$ $\mathrm{VO}_{2} \max$. They then recovered in the laboratory for $4 \mathrm{~h}$, and performed a $40 \mathrm{~km}$ time trial (TT). The supplements were provided immediately after the first bout and $2 \mathrm{~h}$ into the recovery period. Treatments were administered using a doubleblind randomized design. RESULTS: TT time was significantly shorter in CM than $\mathrm{CHO}$ and PLA $(79.43 \pm 2.11$ vs. $85.74 \pm 3.44$ and $86.92 \pm 3.28 \mathrm{~min}$, respectively, $p=<.05)$. Significant treatment differences were found for plasma insulin, glucose, free fatty acids (FFA) and glycerol. Plasma insulin levels were significantly lower in $\mathrm{CM}$ than $\mathrm{CHO}$ at recovery time points $\mathrm{R} 45$ (47.30 \pm 10.54 vs. $58.71 \pm 6.01 \mu \mathrm{U} / \mathrm{ml}, \mathrm{p}<.05), \mathrm{R} 120(14.32 \pm 1.34$ vs. $22.53 \pm 3.37 \mu \mathrm{U} / \mathrm{ml}, \mathrm{p}<.05)$ and REnd $(15.57 \pm 1.53$ vs. $34.35 \pm 4.55 \mu \mathrm{U} / \mathrm{ml}, \quad p<.05)$. Plasma glucose was significantly lower in $\mathrm{CM}$ than $\mathrm{CHO}$ at recovery time points $\mathrm{R} 45(76.61 \pm 3.08$ vs. $101.65 \pm 3.47 \mathrm{mg} / \mathrm{dL}, \mathrm{p}<.05)$ and $\mathrm{R} 120$ (74.72 \pm 2.22 vs. $81.46 \pm 4.87 \mathrm{mg} / \mathrm{dL}, \mathrm{p}<.05)$. While FFA and glycerol were both higher in PLA than in CM and $\mathrm{CHO}$ overall $(p<.05$ for both), FFA and glycerol were higher in $\mathrm{CM}$ than in $\mathrm{CHO}(p<.05$ for both) during recovery and at TTEnd. Blood lactate was significantly higher at R45 and TTEnd in both $\mathrm{CM}$ and $\mathrm{CHO}$ than in PLA, but no differences were found between $\mathrm{CM}$ and $\mathrm{CHO}$. No significant treatment differences were found for myoglobin, CPK, cortisol, and 5 pro- and anti-inflammatory cytokines (TNF- $\alpha$, IL6, IL-10, IL-8, and IL-1Ra). CONCLUSIONS: Chocolate milk provided during recovery can improve subsequent time trial performance in trained cyclists more effectively than an isocaloric $\mathrm{CHO}$ supplement. This may be due to a faster rate of muscle glycogen resynthesis. 